\title{
A HIGH-ACCURACY METHOD TO MAKE MEASUREMENTS ALONG A LINE USING COMPUTER VISION AND LASER DISTANCE SENSORS
}

\author{
Mariana Mascarenhas de Carvalho ${ }^{1}$ \\ Rodrigo Varejão Andreão ${ }^{1}$ \\ João Marques Salomão
}

\begin{abstract}
This paper presents an efficient method to measure real-world distance between interest points of a 3-D object using a camera, two laser distance sensors and Image Processing techniques. This method consists of calculating the distance between interest points of an object in the image plane. Two laser distance sensors placed next to the camera measure accurately the distance between the camera and the object. Moreover, the laser dots generated by the distance sensors are visible in the image, acting as a reference along with the distance measures in the calculations. As a result, thecalculation of the interest point's coordinate on the camera 3-D space is transformed in a real-world distance between interest points. Through a set of experiments, we show that the proposed system measures distancesup to $70 \mathrm{~mm}$ with sub-mm accuracy. The results suggest a potential use of our method in many other Computer Vision applications, including industrial applications.
\end{abstract}

Keywords:3D Measurement. Digital Image Processing. Computer Vision. Instrumentation and Measurement.

\section{MÉTODO DE MEDIÇÃO DE ALTA PRECISÃO UTILIZANDO VISÃO COMPUTACIONAL E SENSOR DE DISTÂNCIA A LASER}

\section{Resumo}

Este artigo apresenta um método eficiente para medir distância entre pontos de interesse em objetos 3D, o qual emprega uma câmera digital, dois sensores de distância à laser e técnicas de processamento de imagem. $\mathrm{O}$ método consiste em se calcular a distância entre pontos de interesse no plano da imagem. Os dois sensores de distância posicionados do lado da câmera medem com precisão a distância entre a câmera e o objeto. Além disso, os dois pontos vermelhos gerados pelos dois sensores de distância são visíveis na imagem, agindo junto com as medidas de distância como referência nos cálculos. Como resultado, as coordenadas dos pontos de interesse no espaço 3D da câmera são transformadas em uma distância real entre os pontos de interesse. A partir de experimentos realizados em laboratório, foi mostrado que o método proposto mede distâncias de até $70 \mathrm{~mm}$ com precisão inferior a $1 \mathrm{~mm}$. Os resultados sugerem que o método proposto pode ser empregado em aplicações de Visão Computacional inclusive aquelas voltadas para a indústria.

Palavras-chaves: Medição 3D. Processamento Digital de Imagem. Visão computacional. Instrumentação e medição. 


\section{INTRODUCTION}

Three-dimensional (3-D) reconstruction is one of the most interesting fields of Computer Vision. Applications of 3-D reconstruction can be seen in many areas, such as autonomous navigation (Básaca-Preciado, 2013), reverse engineering (Tao, 2007), object recognition (Gomes, 2013), and object digitalization (Zhen-Yu, 2012). Developments on this field (Su, 2010) allowed the construction of sophisticated measurement systems (Li, 2012). Frank et al (2000) emphasizes that 3-D shape measurement using optical methods have evolved significantly during the last decades.

General 3-D shape measurement systems can be classified into active and passive systems (Avilagh, 2013)(Muquit, 2006). Active systems employ structure illumination (structure projection, phase shift, moiré topography, etc.) or laser scanning and tend to be very expensive. On the other hand, passive 3-D measurement systems based on stereo vision have the advantages of simplicity and applicability, since such techniques require simple instrumentation. The main problem of passive systems is poor reconstruction quality.

In industry, measurement systems can be highly specialized, since there are constraints regarding the shape measured, the measurement range, etc. Many of the off-the-shelf non-contact industrial measurement systems are based on Image Processing techniques and rely on the fact that the object is at a known position, for example, on a conveyor belt (Song, 2015). However, when this condition is not met, general 3-D shape measurement systems are more suitable.

The objective of this paper is to present a high-accuracy method to measure the distance between interest points along a line on the surface of a 3-D object. The interest points are obtained using Image Processing techniques. Depth information is obtained with the use of the laser distance sensors, and further 3-D reconstruction of the interest points allows measurements in real-world units, such as millimeters. 


\section{MATERIALS AND METHODS}

\subsection{Method overview}

Our method is comprised of a camera, two laser distance sensors and a computer and its objective is to measure the length $L$, along a line on the object surface, as shown in Figure 1.

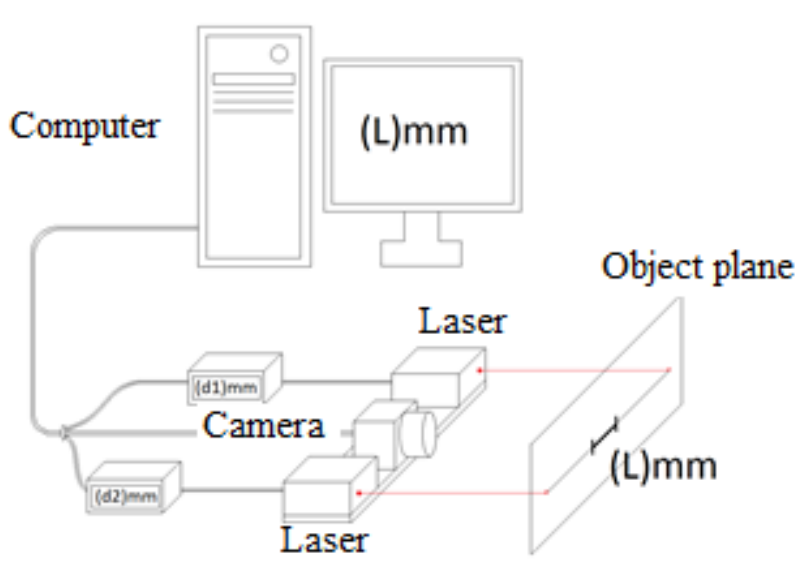

Fig. 1 - Overview of the proposed method

The camera should meet some requirements: good resolution, high frame rate and prepared to work in an industrial environment.

After assembling each equipment according to the Figure 1, a sequence of steps must be carried out until the distance $L$ is obtained as follows:

I. The distance measured by each laser sensors and the image acquired by the camera are sent do the computer (Figure 2); 
Distance measured by laser sensor 1

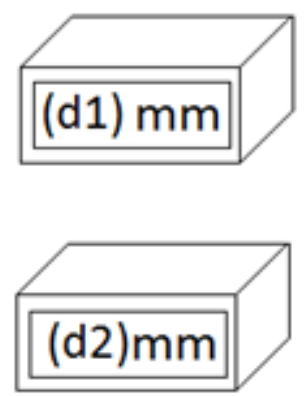

Distance measured by laser sensor 2

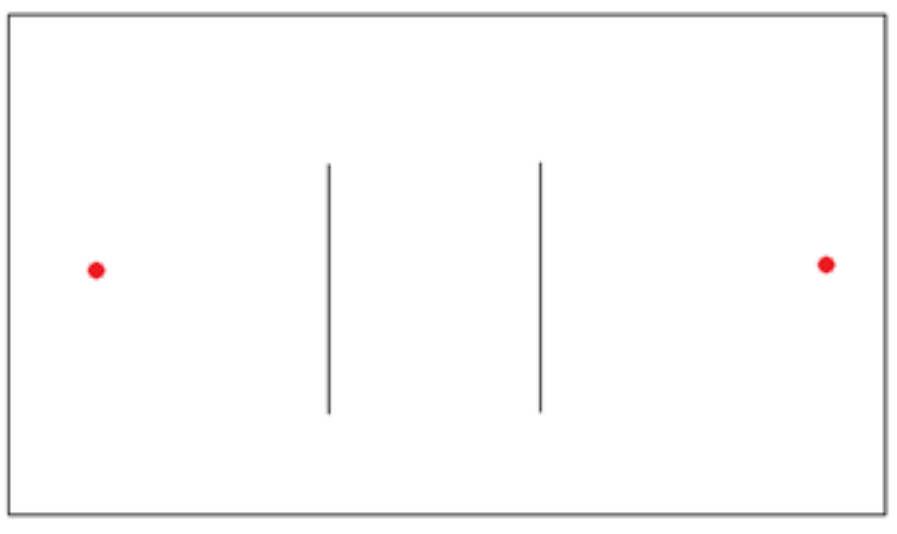

Image acquired by the camera

Fig. 2 - Information obtained the laser sensors and camera

II. The laser dot coordinate on the camera 3-D space are calculated using the distances and the laser beam mapping on the camera 3-D space (Figure 3).

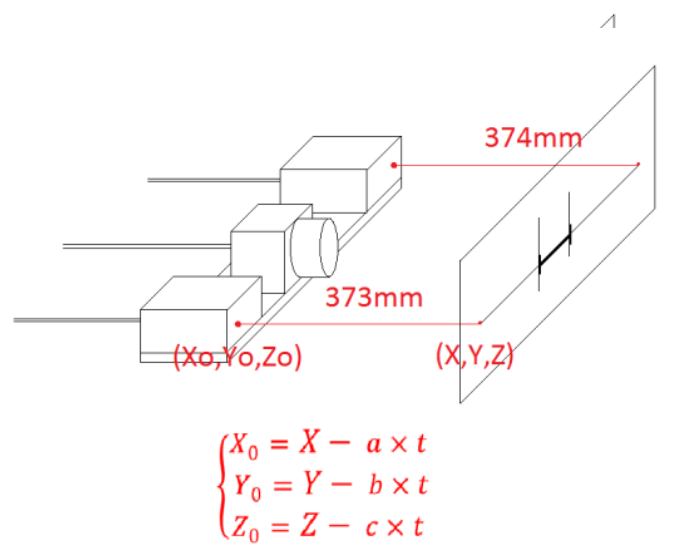

Fig. $3(X 1, Y 1, Z 1$ and $(X 2, Y 2, Z 2$ are the laser dots' coordinates on the camera 3-D space

III. The laser dot coordinates on the image plane $(x, y)$ are calculated using Perspective Transformation (Figure 4). 


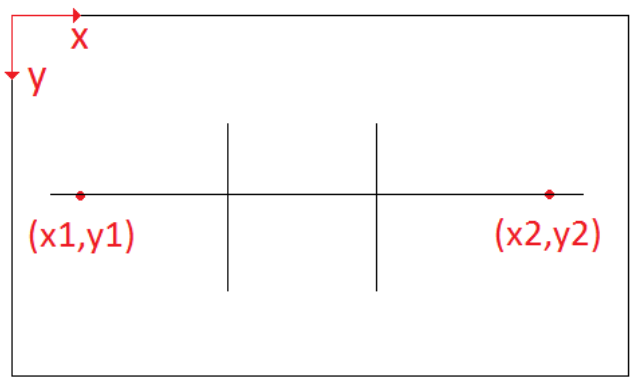

Fig. $4(x 1, y 1)$ and $(x 2, y 2)$ are the laser dot coordinates on the image plane

IV. Interest points are obtained along a line formed by the two laser dots on the image plane (Figure $5)$.

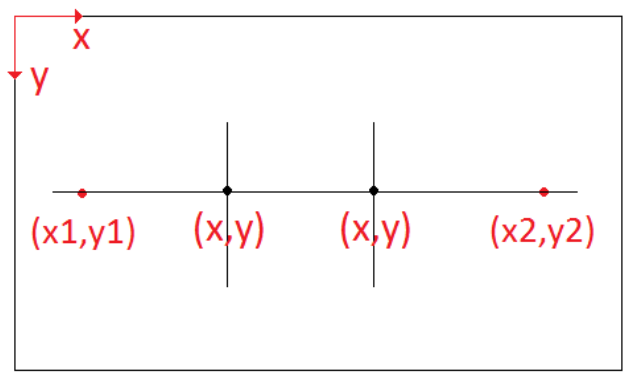

Fig. 5 The interest points are represented in this figure generically as $(x, y)$

V. Interest point's Z coordinate on the camera 3-D space is obtained by interpolation (Figure 6).

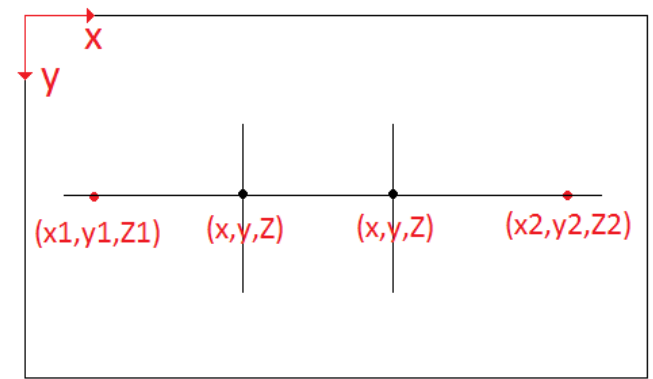

Fig. $6 Z 1$ and $Z 2$ are the $Z$ coordinates of the laser dots on the camera 3-D space

VI. The interest point's coordinate on the camera 3-D space is calculated using Inverse Perspective Transformation (Figure 7). 


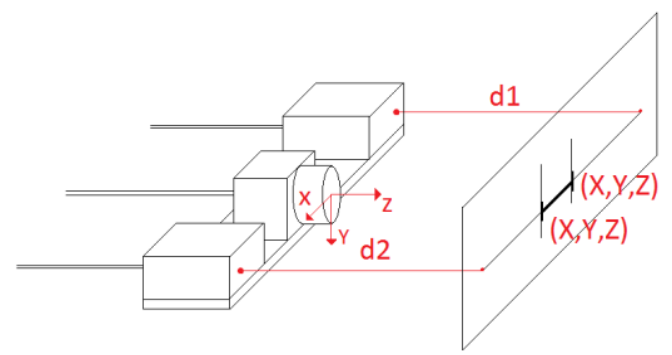

Fig. 7 The interest points' coordinates on the camera 3-D space

VII. The length $L$ between interest points is calculated in real-world units, such as millimeters.
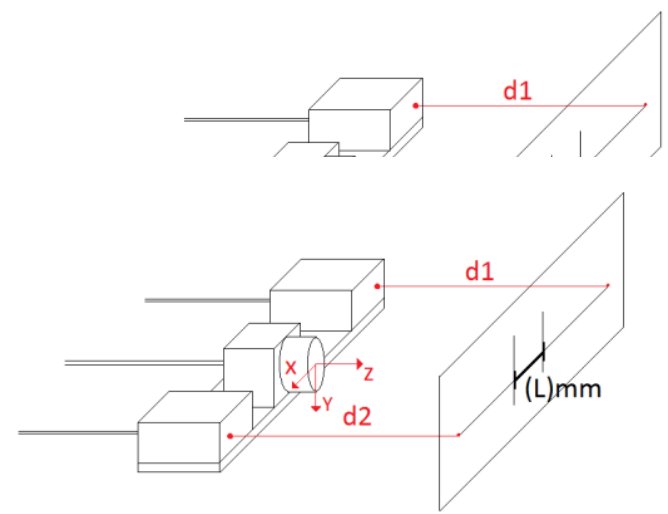

Fig. 8 The laser dots coordinates on the camera 3-D space are calculated

The steps II, III, IV, V, VI and VII are described in detail in sections 2.4, 2.5, 2.6, 2.7 and 2.8, respectively.

\subsection{Camera calibration}

Camera calibration is a fundamental step for many 3-D reconstruction methods. The camera calibration determines the camera matrix and the distortion matrix. Those matrices allow removing distortion from an image, as well as Perspective Transformation calculations.

In this work, pictures of a chessboard pattern in different poses were used in order to perform 
the camera calibration. The source code with the calibration algorithm, based on (Zhang, 2000), was available on OpenCV website. Prior to any of the calculations mentioned in the next sections, the image's distortion was removed.

\subsection{Laser beam mapping on the camera 3-D space}

The method proposed in this work uses information about the laser beam mapping on the camera 3-D space. The laser beam mapping includes the laser distance sensor's coordinate, as well as the laser beam equations on the camera 3-D space, and must be obtained for each of the laser distance sensors.

In order to obtain the laser beam mapping of a laser distance sensor, it is necessary to take a set of pictures containing both a chessboard pattern and the laser dot from the laser distance sensor, and to annotate the distance measured by the sensor in each picture. Each picture is taken with the chessboard pattern in a different distance from the camera.

The presence of the chessboard pattern allows the calculation of the rotation and the translation matrices, $R$ and $T$, which relate the chessboard 3-D space to the camera 3-D space (see Fig. 9).

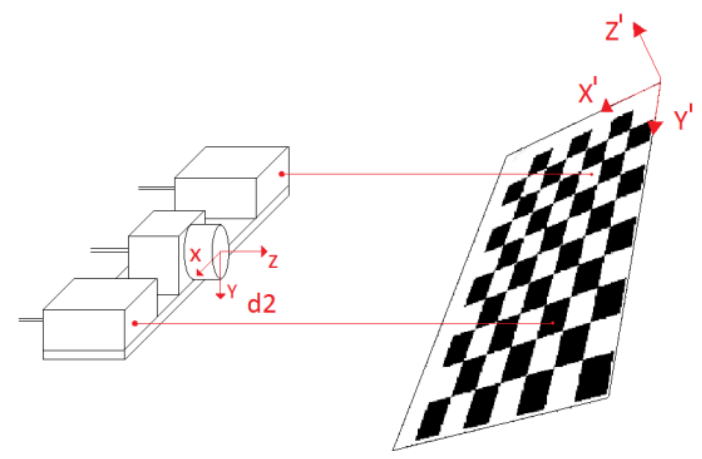

Fig.9 Camera 3-D space, chessboard 3-D space and laser dots

The start point to calculate the laser beam equations is the Perspective Transformation equation (1): 


$$
s\left[\begin{array}{l}
x \\
y \\
1
\end{array}\right]=M\left(R\left[\begin{array}{l}
X^{\prime} \\
Y^{\prime} \\
Z^{\prime}
\end{array}\right]+T\right)(1)
$$

where $M$ is the Camera Matrix, $S$ is the $\mathrm{Z}$ coordinate on the camera 3-D space, and $R$ and $T$ are the rotation and translation matrices.

As the laser dot lies on the chessboard plane, the $Z^{\prime}$ coordinate of the laser dot on the chessboard 3-D space is zero. The 3-D coordinate of the laser dot on the chessboard 3-D space $\left(X^{\prime}, Y^{\prime}, Z^{\prime}\right.$ is then calculated by:

$$
s\left[\begin{array}{l}
x \\
y \\
1
\end{array}\right]=M\left(R\left[\begin{array}{c}
X^{\prime} \\
Y^{\prime} \\
0
\end{array}\right]+T\right)(2)
$$

Given that:

$$
\begin{gathered}
A u x=M\left(R\left[\begin{array}{c}
X^{\prime} \\
Y^{\prime} \\
0
\end{array}\right]+T\right)(3) \\
s=\operatorname{Aux}(3,1)(4)
\end{gathered}
$$

Then:

$$
\begin{gathered}
-T \\
-S\left[\begin{array}{l}
x \\
y \\
1
\end{array}\right]-R \\
{\left[\begin{array}{l}
X^{\prime} \\
Y^{\prime} \\
Z^{\prime}
\end{array}\right]=\left[\begin{array}{c}
X^{\prime} \\
Y^{\prime} \\
0
\end{array}\right]=}
\end{gathered}
$$

And the 3-D-coordinate of the laser dot on the camera 3-D space $(X, Y, Z$ is:

$$
\left[\begin{array}{l}
X \\
Y \\
Z
\end{array}\right]=R\left[\begin{array}{c}
X^{\prime} \\
Y^{\prime} \\
0
\end{array}\right]+T(6)
$$

Laser dots map to the laser beam equation. Repeating the calculation described for each picture, 
several points $\left(X, Y, Z\right.$ from a laser beam are obtained: $\left(X_{1}, Y_{1}, Z_{1},\left(X_{2}, Y_{2}, Z_{2}\right.\right.$, etc. Those points allow the calculation of the laser beam line equations using estimation techniques such as linear regression:

$$
\left\{\begin{array}{l}
X=X_{1}+a \times t(7) \\
Y=Y_{1}+b \times t(8) \\
Z=Z_{1}+c \times t(9)
\end{array}\right.
$$

where $X_{1}, Y_{1}, Z_{1}, a, b, c$ are constants.

Based on the laser beam line equations (7), (8) and (9) and the measurement from the laser distance sensor it is possible to estimate the "origin" of each laser beam, which is the sensor's coordinate $(X o, Y o, Z o)$ on the camera 3-D space. Given a laser dot coordinate $(X, Y, Z$ on the camera 3-D space and the measurement from the laser distance sensor, it is possible to calculate $t$ :

$$
t=\text { distance } /\left(a^{2}+b^{2}+c^{2}\right)(10)
$$

And substituting ton equation (11), (12) and (13) gives the sensor's coordinate $(X o, Y o, Z o)$ :

$$
\left\{\begin{array}{l}
X o=X-a \times t(11) \\
Y o=Y-b \times t(12) \\
Z o=Z-c \times t(13)
\end{array}\right.
$$

Where $X o, Y o, Z o, a, b, c$ are constants.

Notice that the constants $a, b$ and $c$ on equations (11), (12) and (13) have the same value of those from the equations (7), (8) and (9). In order to determine $(X o, Y o, Z o)$ with better accuracy, the calculation of $(X o, Y o, Z o)$ can be repeated for each picture.

Fig. 10 illustrates some of the laser beam mapping steps. The laser dots' coordinates $(X, Y, Z$ are represented by the circles and the sensors' coordinates $(X o, Y o, Z o)$ are represented by the triangles. The Fig. 10 also shows the laser beam lines, plotted with the help of the laser beam equations. 


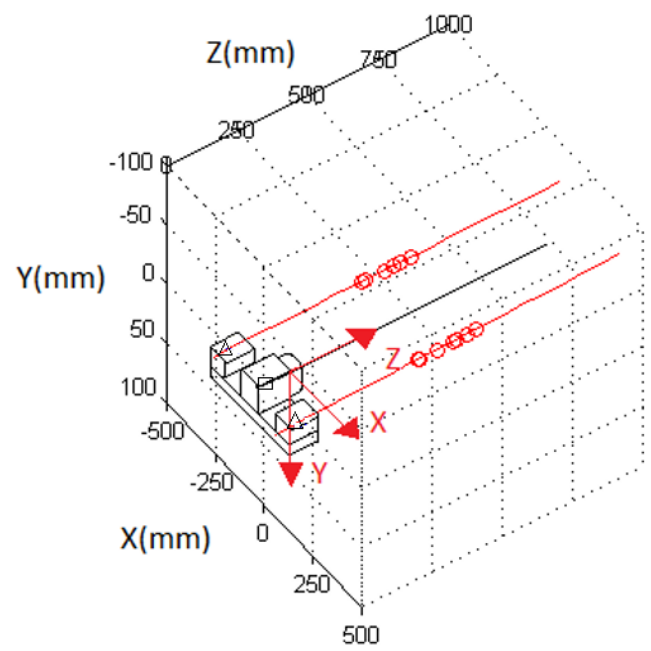

Fig. 10 Laser beam mapping for both left and right laser distance sensors

\subsection{Calculation of the distance sensor's laser dot coordinates on camera 3-D space}

Given the laser beam mapping on the camera 3-D space, it is possible to calculate the laser dot 3-D coordinate $(X, Y, Z$ on the camera 3-D space given the reading from the distance sensors. We assume that the right solution has positive $\mathrm{Z}$, that is, the laser dots are ahead of the camera.

Given the origin of a laser beam on the camera 3-D space $(X o, Y o, Z o)$, it is possible to re-write its line equations (7), (8) and (9) on the camera 3-D space in the following way:

$$
\left\{\begin{array}{l}
X=X o+a \times t(13) \\
Y=Y o+b \times t(14) \\
Z=Z o+c \times t(15)
\end{array}\right.
$$

Where $X o, Y o, Z o, a, b, c$ are constants.

Using the reading from the distance sensor, we can find the positive $t$, which gives a positive Z, using equation (10).

In order to obtain the coordinate $(X, Y, Z$ of the laser dot on the camera 3-D space, it is necessary to substitute the $t$ value on the laser beam line equations (13), (14) and (15). Fig. 3 illustrates the laser dot coordinates of the right sensor and the left sensor on the camera 3-D space as $(X 1, Y 1, Z 1$ and 
$(X 2, Y 2, Z 2$.

\subsection{Calculation of the sensor's laser dot coordinate on the image plane}

The laser dot coordinate on the image plane $(x, y)$ can be calculated using the Perspective Transformation equation:

$$
s\left[\begin{array}{l}
x \\
y \\
1
\end{array}\right]=M\left[\begin{array}{l}
X \\
Y \\
Z
\end{array}\right](16)
$$

Given that:

$$
\begin{aligned}
& A u x=M\left[\begin{array}{l}
X \\
Y \\
Z
\end{array}\right](17) \\
& s=\operatorname{Aux}(3,1)(18)
\end{aligned}
$$

Then:

$$
\left[\begin{array}{l}
x \\
y \\
1
\end{array}\right]=\frac{1}{S} M\left[\begin{array}{l}
X \\
Y \\
Z
\end{array}\right] \text { (19) }
$$

where $M$ is the Camera Matrix and $(X, Y, Z$ is the laser dot coordinate on the camera 3-D space, calculated on the previous sub-section. Fig. 4 illustrates the laser dot coordinates of the right sensor and the left sensor on the image plane namely $(x 1, y 1$ and $(x 2, y 2$.

\subsection{Detection of interest points along the line formed by the laser dots' image points}

An interest point is a coordinate on the image plane, along the line that links the two laser dots, that is interesting for any reason (see Fig. 5). It could be a point from the border of an object, for example, which is useful to measure the object. The interest points can be detected along this line manually or automatically. However, in an industrial application, such as the one presented on section 4 , the interest points are detected using Image Processing techniques. 


\subsection{Calculation of the depth of image points on the line formed by the laser dots}

The coordinates of the laser dots on the camera 3-D space $(X, Y, Z$ can be calculated, as shown in the sub-section 2.4. The depth of any interest point $(x, y)$ along the line formed by the laser dots can then be obtained by linear interpolation, since the depth (Z-coordinate on camera 3-D space) of both laser dots, $Z 1$ and $Z 2$, as well as their image points $(x 1, y 1)$ and $(x 2, y 2)$ are known (see Fig. 6). The Zcoordinate of an image point on the line formed by the laser dots can be calculated by:

$$
Z=Z 1+\frac{(x-x 1) \times(Z 2-Z 1)}{(x 2-x 1)}(20)
$$

or

$$
Z=Z 1+\frac{(y-y 1) \times(Z 2-Z 1)}{(y 2-y 1)}(21)
$$

\subsection{Calculation of interest points 3-D-coordinate on the camera 3-D space}

Given the depth of the interest point and the 2-D coordinate of the point on the image plane, it is possible to calculate its 3-D coordinate ( $X, Y, Z$ on the camera 3-D space (see Fig. 7).

$$
\begin{aligned}
& -\left[\begin{array}{l}
x \\
y \\
1
\end{array}\right](22) \\
& {\left[\begin{array}{l}
X \\
Y \\
Z
\end{array}\right]=s M}
\end{aligned}
$$

\subsection{Calculation of the distance between interest points in real-world units}

The calculation of the distance $L$ (see Fig. 8) between two 3-D points $(X 1, Y 1, Z 1)$ and $(X 1, Y 2, Z 2)$ $Z_{2}$ in real-world units is calculated by:

$$
L=\sqrt{\Delta X^{2}+\Delta Y^{2}+\Delta Z^{2}}(23)
$$

where $\Delta X=X 2-X 1, \Delta Y=Y 2-Y 1 \quad e \Delta Z=Z 2-Z 1$.

\section{METHOD VALIDATION}

\subsection{Validation experiment setup}

The validation experiment was designed to check that the method developed works, and find its accuracy. Previous to the experiment, the camera parameters were obtained with camera calibration, as 
described on section 2.2. After that, the camera and laser distance sensors were mounted on an acrylic support. After mounting, the laser beam mapping was obtained for both right and left sensor, as described on section 2.3.

The experiment consisted on placing the system in front of a white wall, and making measurements along a line on the wall (see Fig. 11). The camera used was a Basler Ace acA2000165um (see Table 1). The camera lenses were the Fujinon HF9HA-1B (see Table 2) and the laser distance sensors were the Keyence IL-600 (see Table 3).

Table 1 Camera specifications

\begin{tabular}{|c|c|}
\hline $\begin{array}{c}\text { Resolution (HxV } \\
\text { pixels) }\end{array}$ & px \\
\hline Frame rate & $165 \mathrm{fps}$ \\
\hline Max. ImageCircle & $2 / 3$ inch \\
\hline
\end{tabular}

Table 2 Lenses specifications

\begin{tabular}{|c|c|}
\hline Focal length & $9 \mathrm{~mm}$ \\
\hline Angular field of view (for $2 / 3$ inch) & $52^{\circ} 06^{\prime} \times$ \\
$40^{\circ} 16^{\prime}$ \\
\hline
\end{tabular}

Table 3 Laser distance sensor specifications

\begin{tabular}{|c|c|}
\hline $\begin{array}{c}\text { Referencedistance } \\
\text { Measurement } \\
\text { range }\end{array}$ & 200 to $1000 \mathrm{~mm}$ \\
\hline Spot diameter & Approx. $\varnothing 1.6 \mathrm{~mm}$ \\
\hline Linearity & $\pm 0.25 \%$ of F.S. $(200$ to \\
\hline
\end{tabular}



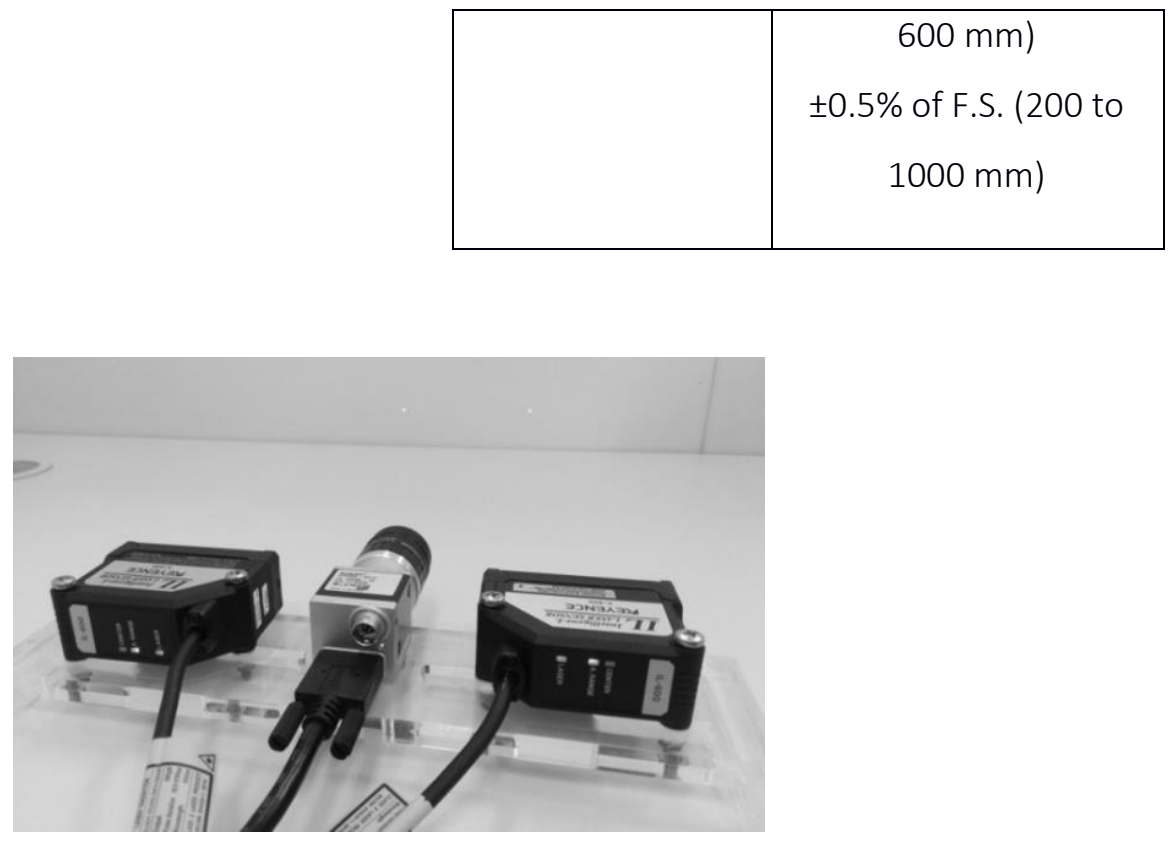

Fig. 11 Proposed system in front of a white wall

The objective of this experiment setup was to measure the distance between the marks with the proposed system and compare to the measurement obtained with a paquimeter. On the wall, a line was drawn connecting the laser dots from the laser distance sensors. Along this line, two vertical marks were made. The interest points were the points where the vertical marks hit the line (see Fig. 12).

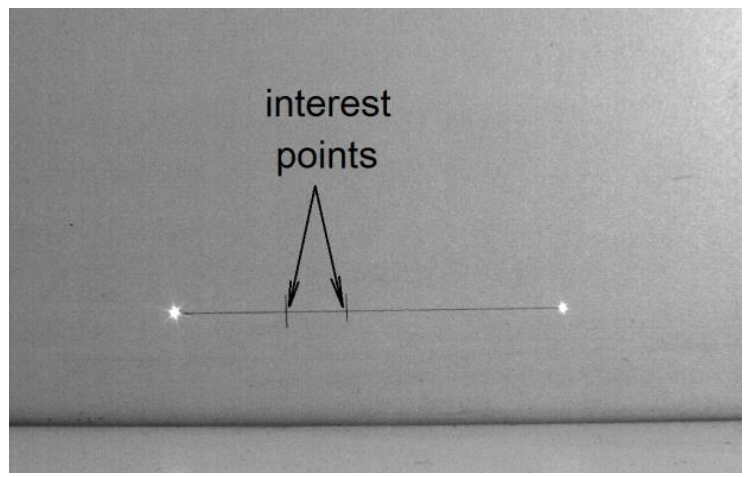

Fig. 12 Interest points along the line formed by the laser dots 
The experiment consisted of three rounds. On each of them, two marks were drawn, and the width was measured with a paquimeter. After that, the same measurements were made with the proposed system, varying the distance between the system and the wall from $400 \mathrm{~mm}$ to $600 \mathrm{~mm}$, with $50 \mathrm{~mm}$ increments. The distance was defined according to the requirements of an industrial environment.The coordinates of the interest points on the image plane were obtained manually, using Pylon Viewer software.

\subsection{Results}

The width obtained using the paquimeter and the proposed system in each of the three rounds can be seen on Table 4 .

Table 4 Data collected from experiment

\begin{tabular}{|c|c|c|c|c|c|}
\hline $\begin{array}{c}\text { Width measured } \\
\text { with a paquimeter } \\
(\mathbf{m m})\end{array}$ & \multicolumn{5}{|c|}{$\begin{array}{c}\text { Width measured with the } \\
\text { proposed system (mm) }\end{array}$} \\
\hline $25,9 \pm 0,1$ & 25,7 & 25,9 & 25,9 & 25,9 & 25,8 \\
\hline $5,1 \pm 0,1$ & 5,1 & 5,2 & 5,2 & 5,1 & 5,2 \\
\hline $70,0 \pm 0,1$ & 70,1 & 70,1 & 69,9 & 70,1 & 69,9 \\
\hline
\end{tabular}

The statistical analysis of the data shown in Table 4are presented in Table 5.

Table 5 Statistical measurements obtained system

\begin{tabular}{|c|c|c|c|}
\hline $\begin{array}{c}\text { Width measured } \\
\text { with a paquimeter } \\
\text { (mm) }\end{array}$ & $25.9 \pm 0.1$ & $5.1 \pm 0.1$ & $70.0 \pm 0.1$ \\
\hline $\begin{array}{c}\text { Mean error with } \\
\text { de proposed } \\
\text { system (mm) }\end{array}$ & -0.06 & 0.06 & 0.10 \\
\hline $\begin{array}{c}\text { Standard } \\
\text { deviation of the } \\
\text { error (mm) }\end{array}$ & 0.089 & 0.055 & 0.212 \\
\hline $\begin{array}{c}\text { 95\% Confidence } \\
\text { Interval(mm) }\end{array}$ & 0.256 & 0.157 & 0.609 \\
\hline
\end{tabular}

analysis from the through the proposed 
The results on Table 5 show that the proposed system has sub-mm accuracy. Other Computer Vision based measurement systems, such as the system presented by (Zhang, 2012), measured an object of $80 \mathrm{~mm}$ and obtained a mean error of $0.15 \mathrm{~mm}$ and a standard deviation of $0.272 \mathrm{~mm}$.

\subsection{Considerations on method accuracy}

If the interest point represented the exact border of the marks, the laser distance sensors would give exact distances, and the line on the surface of the object would be a perfect line, the proposed method would have no error associated with it. However, considering that all propositions above are not valid, it is important to outline the factors that contribute more to the method accuracy on the validation experiment.

Given that the uncertainty associated with the laser distance sensors was less than $0.25 \%$ of the measured value, its contribution on the system uncertainty can be discarded. As the surface was a wall, if the line on the surface of the wall was not a perfect line, it was very close to that, and the effect of the line on the system uncertainty can be discarded too.

The pixel length is the horizontal length of a pixel in an image in real world units such as millimeters. Considering the horizontal angle of the selected lens, the number of horizontal pixels on the image, and the distance d between the system and the wall (see Fig. 13), the pixel length varies according to equation (25). 


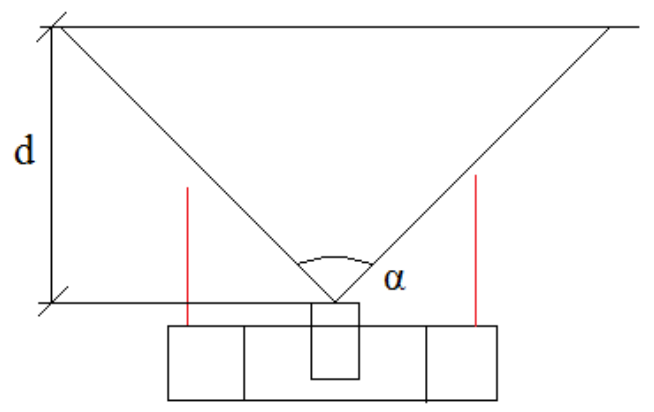

Fig. 13 Pixel horizontal length calculation

$$
\begin{gathered}
2 \times d \times \tan \frac{0.5 \times \alpha}{\text { horizontalresolution }} \\
\text { pixellength }= \\
26^{\circ} 03^{\prime \prime} \\
2 \times d \times \tan \frac{(\text { ) }}{2048} m m(25) \\
\text { pixellength }=
\end{gathered}
$$

Comparing the pixel length for each distance of the validation experiment, on Table 6 , to the uncertainty associated with each measurement, on Table 5, it can be seen that the uncertainty associated with each measurement is between 1 and 2 pixel lengths. This error can be associated with the image discretization, and the impossibility of selecting the exact border of the marks. In order to improve the proposed system accuracy, it is possible to increase the number of horizontal pixels on the image, by selecting a camera with higher resolution.

Table 6 Pixel length given the distance $d$

\begin{tabular}{|l|l|l|l|l|l|}
\hline Distance between the system and the wall & 400 & 450 & 500 & 550 & 600 \\
\hline
\end{tabular}




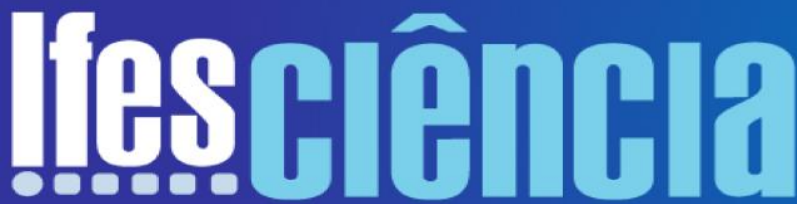

\begin{tabular}{|c|c|c|c|c|c|}
\hline$(\mathrm{mm})$ & & & & & \\
\hline Pixel length $(\mathrm{mm})$ & 0,166 & 0,187 & 0,207 & 0,228 & 0,249 \\
\hline
\end{tabular}

\section{CONCLUSION}

This work presented a Computer Vision based method that measures the width along a line on the surface of a 3-D object. The experiments performed in the laboratory showed that the proposed method achieved good accuracy and could be used in a real world application.

Our proposed system could be adapted to carry out measurements of a plane, after the introduction of a third distance sensor.

Finally, the effect of the light on the measurements was not tested and more experiments are necessary in order to verify the need of a dedicated light.

\section{REFERENCES}

AVILAGH, A.; REZAIE, A. Accuracy enhancement of three-dimensional reconstruction using phaseshifting shadow moire. Journal of Electronic Imaging, v. 22, n. 2, 2013. ISSN 1017-9909.

BÁSACA-PRECIADO, L. C. et al.; Optical 3-D laser measurement system for navigation of autonomous mobile robot. Optics and Lasers in Engineering, v. 54, p. 159-169, 2013.

FRANK, C.; GORDON, M. B.;MUMIN, S. Overview of three-dimensional shape measurement using optical methods. Optical Engineering, v. 39, p. 10, 2000.

GOMES, R. B.; DA SILVA, B. M. F.; ROCHA, L. K. M.; AROCA, R. V.; VELHO, L. C. P. R.; GONCCALVES, L. M. G. Efficient 3-D object recognition using foveated point clouds. Computers \& Graphics, v. 37, n. 5, p. 496-508, 2013.

LI, W.; ZHANG, D.; LU, G.; LUO, N. A Novel 3-D Palmprint Acquisition System. Ieee Transactions On Systems Man And Cybernetics Part A-Systems And Humans, v. 42, n. 2, p. 443-452, 2012.

MOLLEDA, J.; USAMENTIAGA, R.; GARCIA, D. F.; BULNES, F. G.; EMA, L. Shape Measurement of Steel Strips Using a Laser-Based Three-Dimensional Reconstruction Technique. Industry Applications, IEEE Transactions, v. 47, n. 4, p. 1536-1544, 2011. 
MUQUIT, M. A.; SHIBAHARA, T.; AOKI, T. A high- accuracy passive 3D measurement system using phase-based image matching. Ieice Transactions On Fundamentals Of Electronics

Communications And Comput, v. E89A, n. 3, p. 686-697, 2006.

SONG, L. M. et al.; A non-contact real-time measurement of lamp dimension based on machine vision. Optoelectron. Lett., v. 11, n. 2, p. 145-148, 2015.

SU, X.; ZHANG, Q. Dynamic 3-D shape measurement method: A review. Optics and Lasers in Engineering, v. 48, n. 2, p. 191-204, 2010.

TAO, J.; JIYONG, K. A 3-D point sets registration method in reverse engineering. Computers \& Industrial Engineering, v. 53, n. 2, p. 270-276, 2007.

ZHANG, Z. A flexible new technique for camera calibration. Pattern Analysis and Machine Intelligence, IEEE Transactions. v. 22, n. 11, p. 1330-1334, 2000.

ZHANG, Z. F.; GAO, Z.; LIU, Y. Y.; JIANG, F. C.; YANG, Y. L.; REN, Y. F.; ZHANG, X. D. (2012). Computer Vision Based Method and System for Online Measurement of Geometric Parameters of Train Wheel Sets. Sensors (Basel, Switzerland), 12(1), 334-346. http://doi.org/10.3390/s120100334

ZHEN-YU, Z.; ShUAI, Z.; SHING-CHOW, C.; HEUNG-YEUNG, S. Object-Based Rendering and 3D Reconstruction Using a Moveable Image-Based System. Circuits and Systems for Video Technology, IEEE Transactions, v. 22, n. 10, p. 1405-1419, 2012. 